\title{
Coherent Fiber-Optic Links for Transmission and Signal Processing in Microwave and Millimeter-Wave Systems
}

\section{Gliese, Ulrik Bo}

Published in:

Microwave Photonics, 1998. MWP '98. International Topical Meeting on

Link to article, DOI:

10.1109/MWP.1998.745666

Publication date:

1998

Document Version

Publisher's PDF, also known as Version of record

Link back to DTU Orbit

Citation (APA):

Gliese, U. B. (1998). Coherent Fiber-Optic Links for Transmission and Signal Processing in Microwave and Millimeter-Wave Systems. In Microwave Photonics, 1998. MWP '98. International Topical Meeting on (pp. 211214). IEEE. https://doi.org/10.1109/MWP.1998.745666

\section{General rights}

Copyright and moral rights for the publications made accessible in the public portal are retained by the authors and/or other copyright owners and it is a condition of accessing publications that users recognise and abide by the legal requirements associated with these rights.

- Users may download and print one copy of any publication from the public portal for the purpose of private study or research.

- You may not further distribute the material or use it for any profit-making activity or commercial gain

- You may freely distribute the URL identifying the publication in the public portal 


\title{
Coherent Fiber-Optic Links for Transmission and Signal Processing in Microwave and Millimeter-Wave Systems
}

\author{
U. Gliese \\ Center for Broadband Telecommunications, Department of Electromagnetic Systems, \\ Technical University of Denmark, Building 348, DK-2800 Lyngby, Denmark \\ Phone: +45 458814 44, Fax: +45 459316 34, E-mail: ug@emi.dtu.dk
}

\begin{abstract}
The principles of coherent fiber-optic links are presented and the transmission and signal processing capabilities offered to microwave and millimeter-wave systems are discussed. Furthermore, an overview of implemented transmitter types and link experiments is given.
\end{abstract}

\section{Introduction}

Fiber-optic links are gaining increasing interest for implementation of transmission as well as signal processing functions in microwave and millimeter-wave systems.

The basic outline for a fiber-optic link is shown in Fig. 1. Basically, the link transports a signal from its input to its output. If the signal remains unaltered, the link is transparent and its only function is signal transmission. On the other hand, if the signal is intentionally altered by the link, it also performs signal processing. This added functionality may be desirable in many systems and may enable a number of new applications. At present, the potential of such multifunctional links is increasingly recognized [1]-[6]. In coherent links, the signal processing functions can most often be obtained without significant added complexity and cost and without degradation of the transmission performance.

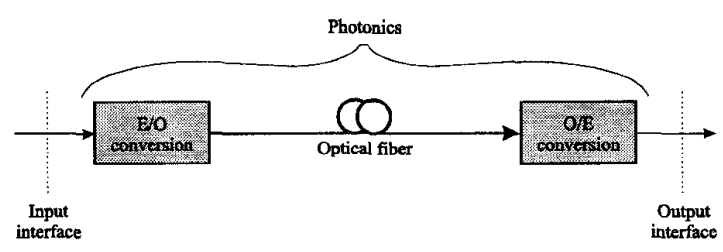

Figure 1: Schematic for the fiber-optic link.

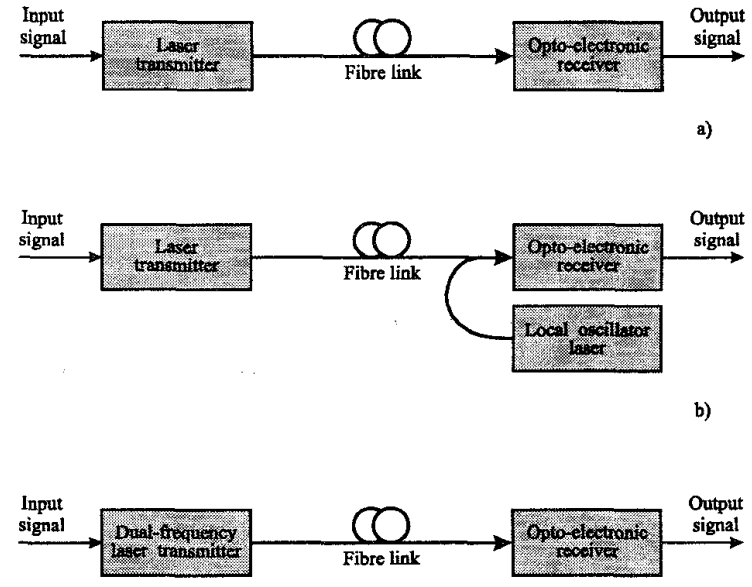

c)

Figure 2: Schematics for a) IM-DD links, b) HD coherent links, and c) RHD coherent links.

\section{Principles of coherent links}

Fiber-optic links may be implemented with coherent or non-coherent techniques. The three resulting link types are shown in Fig. 2. A detailed description of the non-coherent intensity modulated direct detection (IM-DD) link type can be found in [7], [8]. In the heterodyne detection (HD) and the remote heterodyne detection (RHD) links, the interaction between two laser signals form the basis for the detection process, and the detected signal current is given as

$$
\begin{aligned}
& i_{\mathrm{s}}(t)= \\
& 2 R \sqrt{p_{1}(t) p_{2}(t)} \cdot \cos \left[\left\{\omega_{1}(t)-\omega_{2}(t)\right\} t+\phi_{1}(t)-\phi_{2}(t)\right]
\end{aligned}
$$

where $R$ is the responsivity of the photodetector, 
$t$ is the time, and $p(t)$ is the instantaneous power, $\omega(t)$ is the instantaneous frequency and $\phi(t)$ is the instantaneous phase of the laser signals. The equation shows that it is necessary to maintain a well defined correlation between the frequency and phase of the two signals. This makes coherent links more complex than non-coherent links. However, as discussed in this paper, it also offers a number of advantages. More detailed descriptions of the $\mathrm{HD}$ principle can be found in [9] and of the RHD principle in [5], [6], [8].

This paper is focused on RHD coherent links. In these, both laser signals are generated at the transmitter end of the link. This makes it significantly easier to maintain frequency and phase correlation as compared to HD links.

\section{Transmission capabilities}

The transmission properties and capabilities of coherent RHD links are, in many respects, different from those of the IM-DD links. The higher complexity of coherent links pays off in terms of:

- Higher link gain [10].

- Comparable or higher linearity [10].

- Comparable or higher CNR [10].

- Lower sensitivity to chromatic dispersion [8].

The link gain can be much higher since a modulation depth of unity can be achieved without degradation of linearity (see the equation) and since the power from two lasers is often involved. The CNR improvement depends on the involved noise sources. Incorporation of optical preamplifiers in the DD receivers will reduce the CNR advantage offered by the coherent detection.

\section{Signal processing capabilities}

In addition to attractive transmission capabilities, the coherent links readily offer photonic signal processing possibilities. This is evident from the equation where it is seen that changes in either amplitude, frequency or phase applied to one of the laser signals will result in proportional changes of the signal at the output of the link.

This feature opens up for photonic implementation of a variety of functionalities in microwave and millimeter-wave systems:
- Transmission.

- Amplitude control.

- Frequency control.

- Phase control.

- Time delay control.

- Filtering.

- Modulation and demodulation.

- Frequency conversion.

- Signal recovery.

Photonic implementation of these functionalities may be advantageous in some existing applications and may open up for new applications that were not possible beforehand.

All of the listed functionalities are, to a large extent, equally important. It is, however, impossible to give a complete survey of them all. In the remainder of the paper, which deals with experimental results, the focus is placed on transmitter concepts and RHD link experiments demonstrating transmission, modulation, frequency conversion and signal recovery.

\section{Dual-frequency laser transmitters}

The RHD links require dual-frequency laser transmitters. These can be implemented in different ways and a significant number of concepts have been proposed and experimented:

- Dual mode laser (DML) transmitters [11].

- Pulsed laser (PL) transmitters [12].

- Optical frequency shifter (OFS) transmitters:

- Splitting and shifting (SS) [13], [14].

- SSB modulation [15]-[17].

- Suppressed carrier DSB modulation [18].

- Optical injection locked loop (OILL) transmitters [19]-[21].

- Optical phase locked loop (OPLL) transmitters [22]-[25].

- Optical feedforward modulator (OFFM) transmitters [26].

The above transmitters, some of which are conceptually very different, basically generate two phase correlated optical signals that can be separately altered in intensity, frequency and phase. All of them have been successfully used in link experiments. 
Table 1: Overview of RHD link transmission and signal processing experiments.

\begin{tabular}{|l|l|l|l|r|l|r|r|}
\hline Functionality & Tx concept & LF & \multicolumn{1}{l|}{ IF } & \multicolumn{1}{l|}{ RF } & Modulation & Year & Ref. \\
\hline Modulation & OPLL & $1 \mathrm{~Gb} / \mathrm{s}$ & & $9 \mathrm{GHz}$ & $1 \mathrm{~Gb} / \mathrm{s}$ QPSK & 1994 & {$[27]$} \\
\hline Modulation & OFS-DSB & $140 \mathrm{Mb} / \mathrm{s}$ & & $36 \mathrm{GHz}$ & $140 \mathrm{Mb} / \mathrm{s}$ BPSK & 1994 & {$[28]$} \\
\hline Up-conversion & OFS-SSB & & $50 \mathrm{MHz}$ & $650 \mathrm{MHz}$ & No modulation & 1994 & {$[29]$} \\
\hline Up-conversion & OPLL & & $2 \mathrm{GHz}$ & $9 \mathrm{GHz}$ & $100 \mathrm{Mb} / \mathrm{s} \mathrm{DPSK}$ & 1994 & {$[30]$} \\
\hline Up-conversion & PL & & $2 \mathrm{GHz}$ & $58 \mathrm{GHz}$ & $155 \mathrm{mb} / \mathrm{s} \mathrm{BPSK}$ & 1996 & {$[31]$} \\
\hline Up-conversion & OFS-SSB & & $2 \mathrm{GHz}$ & $39 \mathrm{GHz}$ & $\begin{array}{l}155 \mathrm{mb} / \mathrm{s} \mathrm{BPSK} \\
+\end{array}$ & 1997 & {$[32]$} \\
\hline Up-conversion & OILL & & $140 \mathrm{MHz}$ & $19 \mathrm{GHz}$ & $140 \mathrm{Mb} / \mathrm{s}$ OQPSK & 1997 & {$[20]$} \\
\hline Up-conversion & OILL & & $1 \mathrm{GHz}$ & $64 \mathrm{GHz}$ & $140 \mathrm{Mb} / \mathrm{s}$ OQPSK & 1998 & {$[33]$} \\
\hline Transparency & OFFM & & & $39 \mathrm{GHz}$ & $300 \mathrm{Mb} / \mathrm{s} \mathrm{BPSK}$ & 1994 & {$[34]$} \\
\hline Transparency & DML & & & $60 \mathrm{GHz}$ & No modulation & 1996 & {$[11]$} \\
\hline Transparency & OFS-SSB & & & $12 \mathrm{GHz}$ & $51.8 \mathrm{Mb} / \mathrm{s} \mathrm{BPSK}$ & 1997 & {$[35]$} \\
\hline Transparency & OFS-SSB & & & $38.1 \mathrm{GHz}$ & $155 \mathrm{Mb} / \mathrm{s} \mathrm{BPSK}$ & 1997 & {$[36]$} \\
\hline Transparency & OFS-SSB & & & $10 \mathrm{GHz}$ & $2.49 \mathrm{~Gb} / \mathrm{s} \mathrm{BPSK}$ & 1997 & {$[37]$} \\
\hline Transparency & DML & & & $36.8 \mathrm{GHz}$ & $51.8 \mathrm{Mb} / \mathrm{s} \mathrm{PSK}$ & 1998 & {$[38]$} \\
\hline Signal recovery & OPLL & & & $7.6 \mathrm{GHz}$ & $27 \mathrm{MHz}$ FM & 1994 & {$[39]$} \\
\hline
\end{tabular}

\section{Link experiments}

An overview of the link experiments that have been carried out using coherent RHD is given in Table 1. A large number of different functionalities, transmitter concepts and signal formats have been experimented with excellent results. For all of the experiments, the indicated functionality describes the signal processing that is carried out by the link in addition to transmission.

All of the transmitter concepts have been applied although not for all functionalities. As an example, it is only the OPLL transmitter that can be used for transparent signal recovery of a microwave signal that has been degraded by additive noise [5], [39].

The SSB modulation transmitter is by far the most popular. This is because of its lower complexity as compared to especially the OILL and OPLL transmitters. However, the latter do enable a better performance in terms of link gain and CNR without the addition of optical amplifiers. This is because the full power from two separate lasers is ideally available for transmission. Furthermore, the two laser signals are readily available for individual photonic processing.
The experiments clearly demonstrate the feasibility of coherent fiber-optic RHD links. As evident, most focus on transparent transmission and frequency conversion. However, the photonic signal processing potential of coherent links can be taken much further. This may lead to many new innovative system applications.

\section{Conclusion}

Coherent fiber-optic RHD links exhibit attractive transmission capabilities as compared to IM-DD links. In addition, they also offer the capabilities to perform a large number of different signal processing functionalities. An overview of link experiments demonstrating, modulation, frequency conversion, and signal recovery has been given. In many applications, such links may be much more desirable than transparent links. As opposed to the conventional DD links, the RHD links can in many cases be optimized to the specific application. This may significantly influence performance, cost, power consumption, etc. When comparing DD links and RHD links this must be taken into account, and the entire system must be evaluated in its entirety from end-to-end. 


\section{References}

[1] G.K. Gopalakrishnan, et. al., "A low-loss downconverting analog fiber-optic link," IEEE Trans. MTT, vol. 43, no. 9 , 1995 , pp. 2318-2323.

[2] U. Gliese, "Multi-functional fibre-optic microwave and millimeter-wave links," Proc. URSI General Assembly, Lille, France, August, 1996, pp. 638

[3] L. Noël, et. al., "Novel techniques for high-capacity 60$\mathrm{GHz}$ fiber-radio transmission systems," IEEE Trans. MTT, vol. 45 , no. 8,1997 , pp. 1416-1423.

[4] K.J. Williams, et. al., "Photonic Microwave Signal Processing," Proc. IEEE MWP, September, 1997, Dusiburg Germany, pp. 187-190.

[5] U. Gliese, et. al., "Multi-functional fibre-optic microwave links based on remote heterodyne detection," IEEE Trans. MTT, vol. 46, no. 5, 1998 .

[6] U. Gliese, "Multi-functional fibre-optic microwave links," Opt. and Quan. Elec., 1998

[7] C. Cox III, et. al., "Techniques and performance of intensity-modulation direct-detection analog optical links," IEEE Trans. MTT, vol. 45, no. 8, 1997, pp. 1375-1383

[8] U. Gliese, et. al., "Chromatic dispersion in fiber-optic microwave and millimeter-wave links," IEEE Trans. MTT, vol. 44 , no. 10,1996 , pp. 1716-1724.

[9] R. Gross, et. al., "Multichannel coherent FSK experiments using subcarrier multiplexing techniques," IEEE JLT, vol. 8 , no. 3, 1990 , pp. $406-414$

[10] T.N. Nielsen, et. al., "Performance evaluation of fibre-optic microwave links," ESA, ESTEC Contract Report, Contract No. 134212, Technical University of Denmark, Department of Electromagnetic Systems, R590, October, 1994.

[11] D. Wake, et. al., "Transmission of $60-\mathrm{GHz}$ signals over $100 \mathrm{~km}$ of optical fiber using a dual-mode semiconductor laser source," IEEE PTL, vol. 8, no. 4, 1996, pp. 578-580.

[12] D.Y. Kim, et. al., "Ultrastable millimetre-wave signal generation using hybrid modelocking of a monolithic DBR laser," IEE Elec. Lett., vol. 31, no. 9, 1995, pp. 733-734.

[13] M. Tamburrini, et. al., "Optical feed for a phased array microwave antenna," IEE Elec. Lett., vol. 23, no. 13, 1987 pp. 680-681.

[14] C.L. Wang, et. al., "Permanent magnet-based guided-wave magnetooptic Bragg cell modules," IEEE JLT, vol. 10, no. 5, 1992, pp. 644-648.

[15] M. Izutsu, et. al., "Integrated optical SSB modulator/frequency shifter," IEEE JQE, vol. 17, no. 11, 1981, pp. 2225-2227.

[16] R.F. Kalman, et. al., "A novel analog optical link with high dynamic range," IEEE PTL, vol. 5, no. 6, 1993, pp. 725728 .

[17] G.H. Smith, et. al., "Technique for optical SSB generation to overcome dispersion penalties in fiber-radio systems," IEE Elec. Lett., vol. 33, no. 1, 1997, pp. 74-75.

[18] J.J. O'Reilly, et. al., "Optical generation of very narrow linewidth millimetre wave signals," IEE Elec. Lett., vol. 28, no. 25,1992 , pp. $2309-2311$.

[19] L. Goldberg, et. al., "Microwave signal generation with injection-locked laser diodes," IEE Elec. Lett., vol. 19 , no. 13,1983 , pp. 491-493.

[20] R.-P. Braun, et. al., "Microwave generation for bidirectional broadband mobile communications using optical sideband injection locking," IEE Elec. Lett., vol. 33 no. 16,1997 , pp. $1395-1396$.
[21] L. Noel, et. al., "Optical millimetre-wave generation technique with high efficiency, purity and stability," IEE Elec. Lett., vol. 32, no. 21, 1996, pp. 1997-1998.

[22] R.C. Steele, "Optical phase-locked loop using semiconductor laser diodes," IEE Elec. Lett., vol. 19, no. 2, 1983, pp. 69-70.

[23] K.J. Williams, et. al., "6-34 GHz offset phase-locking of Nd:YAG 1319 nm nonplanar ring lasers," IEE Elec. Lett., vol. 25 , no. 18,1989 , pp. 1242-1243.

[24] R.T. Ramos, et. al., "Fast heterodyne optical phase-lock loop using double quantum well laser diodes, "IEE Elec. Lett., vol. 28, no. 1, 1992, pp. 82-83.

[25] U. Gliese, et. al., "A wideband heterodyne optical phase locked loop for generation of $3-18 \mathrm{GHz}$ microwave carriers," IEEE PTL, vol. 4, no. 8, 1992, pp. 936-938.

[26] O. Solgaard, et. al., "Millimeter-wave, multigigahertz optical modulation by feedforward phase noise compensation of a beat note generated by photomixing of two laser diodes," IEEE PTL, vol. 5, no. 5, 1993, pp. 574-577.

[27] T.N. Nielsen, et. al., "A Gbit/s QPSK optical microwave transmitter based on a semiconductor optical amplifier phase modulator and phase locked DFB lasers," Tech. Dig. OFC, February, 1994, San Jose, California, pp. 114-115.

[28] H. Schmuck, et. al., "Advanced fibre-optic distribution of $140 \mathrm{Mbit} / \mathrm{s} \mathrm{mm}$-wave signals at $36 \mathrm{GHz}$," Proc. ECOC Firenze, Italy, 1994, pp. 39-44.

[29] R.F. Kalman, et. al., "Demonstration of an analog heterodyne interferometric phase-modulated (HIMP) link," IEEE PTL, vol. 6, no. 10, 1994, pp. 1271-1273.

[30] U. Gliese, et. al., "Frequency Up-Shifting Fiber-Optic Microwave Link," Proc. IEEE MWP, November, 1994 Abbaye de Vaux de Cernay, France, pp. 137-139.

[31] C.H. von Helmolt, et. al., "58-GHz fiber-optic upconverter applicable to wireless communication systems," Tech. Dig OFC, San Jose, California, 1996, pp. 209-210.

[32] G.H. Smith, et. al., "Full-duplex broadband millimetrewave optical transport system for fibre-wireless access," IEE Elec. Lett., vol. 33, no. 13, 1997, pp. 1159-1160.

[33] R.-P. Braun, et. al., "Fiber optic millimeter-wave generation at $64 \mathrm{GHz}$ and spectral efficient data transmission for mobile communications," Tech. Dig. OFC, San Jose California, 1998, pp. 17-18

[34] J.B. Georges, et. al., "Transmission of $300 \mathrm{Mbit} / \mathrm{s}$ BPSK at $39 \mathrm{GHz}$ using feedforward optical modulation," IEE Elec. Lett., vol. 30, no. 2, 1994, pp. 160-161

[35] G.H. Smith, et. al., "Overcomming chromatic-dispersion effects in fiber-wireless systems incorporating external modulators," IEEE Trans. MTT, vol. 45, no. 8, 1997, pp. 1410-1415.

[36] G.H. Smith, et. al., "Full-duplex fiber-wireless system using electrical and optical SSB modulation for efficient broadband millimeter-wave transport," Proc. IEEE MWP September, 1997, Dusiburg, Germany, pp. 223-226.

[37] K. Kitayama, "Highly spectral efficient OFDM wireless networks by using optical SSB modulation," Proc. IEEE MWP, September, 1997, Dusiburg, Germany, pp. 231-234.

[38] C. Lim, et. al., "Implementation of an upstream path in a millimeter-wave fiber-wireless system," Tech. Dig. OFC, San Jose, California, 1998, pp. 16-17

[39] T.N. Nielsen, et. al., "Highly Linear and Transparent 3$18 \mathrm{GHz}$ Optical Microwave Link," Tech. Dig. IEEE MTTS, May, 1994, San Diego, California, pp. 491-494. 